\title{
Association between serum vitamin $D$ and uric acid in the eastern Chinese population: a population-based cross-sectional study
}

\author{
Yingchao Chen ${ }^{\dagger}$, Jing Cheng ${ }^{\dagger}$, Yi Chen $^{\dagger}$, Ningjian Wang, Fangzhen Xia, Chi Chen, Bing Han ${ }^{*}$ and Yingli Lu (D)
}

\begin{abstract}
Background: Uric acid (UA) is the end product of purine metabolism, which is thought to be related to many human diseases, such as nephrolithiasis, gout, cardiovascular disease (CVD), type 2 diabetes mellitus, metabolic syndrome. However, the relationship between serum UA (SUA) and $25(\mathrm{OH})$ D is still unclear in the eastern Chinese population.
\end{abstract}

Methods: We did a population-based observational investigation, which included 12,770 residents living in eastern China. Ultimately, data from 9220 subjects were analyzed. Serum 25(OH) D, SUA, fasting plasma glucose (FPG), fasting insulin, HbA1c and other metabolic parameters were tested. Waist circumference (WC), weight and height were also measured. Questionnaires were collected from these subjects for information on smoking and drinking status.

Results: We enrolled 9220 Chinese adults, including 3681 males (age $55.57 \pm 13.23$ years) and 5539 females (age $54.31 \pm 12.83$ years). The levels of SUA were $352.07 \pm 79.25 \mathrm{nmol} / \mathrm{L}$ and $269.29 \pm 64.68 \mathrm{nmol} / \mathrm{L}$ in males and females, respectively. The proportion of adults with hyperuricemia (HUA) was $12.26 \%$ in the total population. Levels of SUA were positively associated with $25(\mathrm{OH}) \mathrm{D}$, and the incidence of HUA increased $9.4 \%$ for every $10 \mathrm{nmol} / \mathrm{L}$ increase in 25(OH) D $(P<0.001)$.

Conclusions: SUA was positively associated with $25(\mathrm{OH}) \mathrm{D}$ in the eastern Chinese population. Higher levels of serum 25(OH) D may be a potential predictor of HUA.

Keywords: Uric acid, Vitamin D, Hyperuricemia, Public health

\section{Background}

Vitamin D is an essential fat-soluble vitamin for humans. It can be produced in the skin when the epidermis is exposed to ultraviolet $\mathrm{B}$ radiation or it can be obtained from the diet, including ergocalciferol (D2) from plants and cholecalciferol (D3) mostly from marine life. The primary source of vitamin $D$ is the keratinocytes of the skin [1]. Vitamin D is activated by hydroxylases, namely,

\footnotetext{
*Correspondence: foxhb1423@126.com; luyingli2008@126.com

${ }^{\dagger}$ Yingchao Chen, Jing Cheng and Yi Chen contributed equally to this work. Institute and department of Endocrinology and Metabolism, Shanghai Ninth People's Hospital Affiliated to Shanghai Jiaotong University School of Medicine, No.639 Zhizaoju Road, Shanghai, China
}

forms of cytochrome $\mathrm{P} 450$, to become the active hormone $\left(1,25(\mathrm{OH})_{2} \mathrm{D}\right)$. As $25(\mathrm{OH}) \mathrm{D}$ has a significantly longer half-life than $1,25(\mathrm{OH})_{2} \mathrm{D}$, the serum level of $25(\mathrm{OH}) \mathrm{D}$ is considered to be the most stable and reliable indicator of vitamin $\mathrm{D}$ status.

Vitamin $\mathrm{D}$ is generally regarded as an important prohormone, that can participate in regulating the metabolism of calcium phosphate and bone physiology. Recently, an increasing number of studies have shown that vitamin $\mathrm{D}$ is also involved in many other diseases. Through its ubiquitously expressed receptor, calcitriol displays potent anti-angiogenic and anti-inflammatory activity

(c) The Author(s). 2020 Open Access This article is licensed under a Creative Commons Attribution 4.0 International License, which permits use, sharing, adaptation, distribution and reproduction in any medium or format, as long as you give appropriate credit to the original author(s) and the source, provide a link to the Creative Commons licence, and indicate if changes were made. The images or other third party material in this article are included in the article's Creative Commons licence, unless indicated otherwise in a credit line to the material. If material is not included in the article's Creative Commons licence and your intended use is not permitted by statutory regulation or exceeds the permitted use, you will need to obtain permission directly from the copyright holder. To view a copy of this licence, visit http://creativecommons.org/licenses/by/4.0/. The Creative Commons Public Domain Dedication waiver (http://creativecommons.org/publicdomain/zero/1.0/) applies to the data made available in this article, unless otherwise stated in a credit line to the data. 
[2]. The active vitamin D metabolite can alter DNA transcription through vitamin D receptors (VDRs), heterodimerized with retinoic $\mathrm{X}$ receptors, which bind to the regulatory sites in target genes [2].

Serum uric acid (SUA) is the end product of purine metabolism in humans. Most circulating uric acid (UA) is freely filtered in the kidneys, which excrete approximately $60-70 \%$ of the total UA from the body [3]. More than 30 years ago, Ames et al. hypothesized that higher SUA levels might have been beneficial during hominoid evolution because of the antioxidant properties of UA [4]. On the other hand, UA in excess may cause nephrolithiasis and gout. And it has been proposed to be linked to many other human diseases [5]. UA is an independent risk factor for insulin resistance, cardiovascular disease (CVD), nonalcoholic fatty liver disease (NAFLD) $[6,7]$, type 2 diabetes mellitus, metabolic syndrome, and atherosclerosis $[8,9]$. Impaired renal function may increase SUA concentration by decreasing renal excretion [10]. Reduced nephron mass and/or 1- $\alpha$ hydroxylase enzyme activity has been shown to be associated with a decline in $1,25(\mathrm{OH})_{2} \mathrm{D}$ levels in patients with chronic kidney disease (CKD) [11]. Previous studies have found that vitamin D deficiency was a predictor of CKD [12].

Vitamin D insufficiency was found significantly associated with elevated UA among postmenopausal Chinese Han women [13]. Another study showed that lower concentrations of SUA predict lower vitamin D levels in patients with type 2 diabetes and CKD [14]. However, there were few studies focused on vitamin D and UA in the general population. In this study, we intended to investigate the relationship between $25(\mathrm{OH}) \mathrm{D}$ and SUA in the general population. Our research will extend our understanding of the relationship between vitamin D and SUA.

\section{Methods}

\section{Study population}

The Survey on Prevalence in East China for Metabolic Diseases and Risk Factors, 2014 (SPECT-China, 2014) is a population-based cross-sectional survey on the prevalence of metabolic diseases and risk factors in eastern China. The registration number is ChiCTR-ECS14005052_(www.chictr.org). In this study, 12,770 residents from 22 sites in Shanghai Municipality, Zhejiang Province, Jiangsu Province, Anhui Province and Jiangxi Province were enrolled from January 2014 to December 2015. Chinese citizens $\geq 18$ years old who had lived in their current area for $\geq 6$ months were selected. We excluded subjects with severe communication problems, acute illness or who were unwilling to participate. We also excluded those who had no UA data $(n=3,535)$, no vitamin D data $(n=4)$, and gouty arthritis or stage 5 CKD $(n=10)$, as well as those who took anti- osteoporosis drugs $(n=1)$. Ultimately, 9220 subjects were included (Fig. 1). This study was approved by the ethics committee of Shanghai Ninth People's Hospital affiliated with Shanghai Jiaotong University School of Medicine. Written consent was obtained from all the participants.

\section{Measurements and definition}

The homeostasis model assessment of insulin resistance (HOMA-IR) was performed by means of fasting glucose $(\mathrm{mmol} / \mathrm{L}) \times$ fasting insulin $(\mathrm{mIU} / \mathrm{L}) / 22.5$. Weight and height were measured with participants wearing light clothing and no shoes. Body mass index (BMI) was calculated as weight $(\mathrm{Kg}) /$ height $\operatorname{squared}\left(\mathrm{m}^{2}\right)$. Systolic blood pressure (SBP), diastolic blood pressure (DBP) and heart rate were measured three times with a sphygmomanometer (TERUMO-Elemano). The mean of the three records was used in the analysis. Waist circumference (WC) was measured at the level of $1 \mathrm{~cm}$ above the umbilicus. Hyperuricemia (HUA) was defined by UA > $420 \mu \mathrm{mol} / \mathrm{L}$ in men and $>360 \mu \mathrm{mol} / \mathrm{L}$ in women. Demographic information and lifestyle risk factors were gathered from standard questionnaires by trained stuff. Drinking and smoking status was divided into never drinking/smoking and past or current drinking/smoking.

\section{Assessment of biomarkers}

Blood samples were obtained after fasting for at least 8 $\mathrm{h}$; the samples were immediately centrifuged $(2000 \mathrm{rpm}$ for $15 \mathrm{~min}$ ) at room temperature, and stored at $-20^{\circ} \mathrm{C}$ when collected and shipped by air in dry ice within 2-4 $\mathrm{h}$ of collection to a central laboratory certified by the College of American Pathologists. All plasma and serum samples were frozen at $-80^{\circ} \mathrm{C}$ after laboratory testing. Biochemical indexes, including the fasting plasma glucose (FPG), total cholesterol (TC), triglycerides (TG), low-density lipoprotein (LDL), alanine aminotransferase (ALT) were analyzed by Beckman Coulter AU680 (Bera, USA). Serum 25(OH) D (SIEMENS ADVIA Centaur XP, Siemens, Germany) and insulin (Abbott i2000 SR, Chicago, USA) were measured using the chemiluminescence method. Glycated hemoglobin (HbA1c) was detected using high-performance liquid chromatography (HPLC) with MQ-2000PT (Medconn Technology, Shanghai, China) using a commercial reagent (HuaChen biological reagent co., LTD, Shanghai, China).

\section{Statistical analysis}

Data analyses were performed using IBM SPSS Statistics, Version 22 (IBM Corporation, Armonk, New York). All $P$ values were two-sided. $P<0.05$ was considered statistically significant. Continuous variables were summarized as mean \pm standard deviation (SD). Categorical variables were expressed as a percentage (\%). UA was 


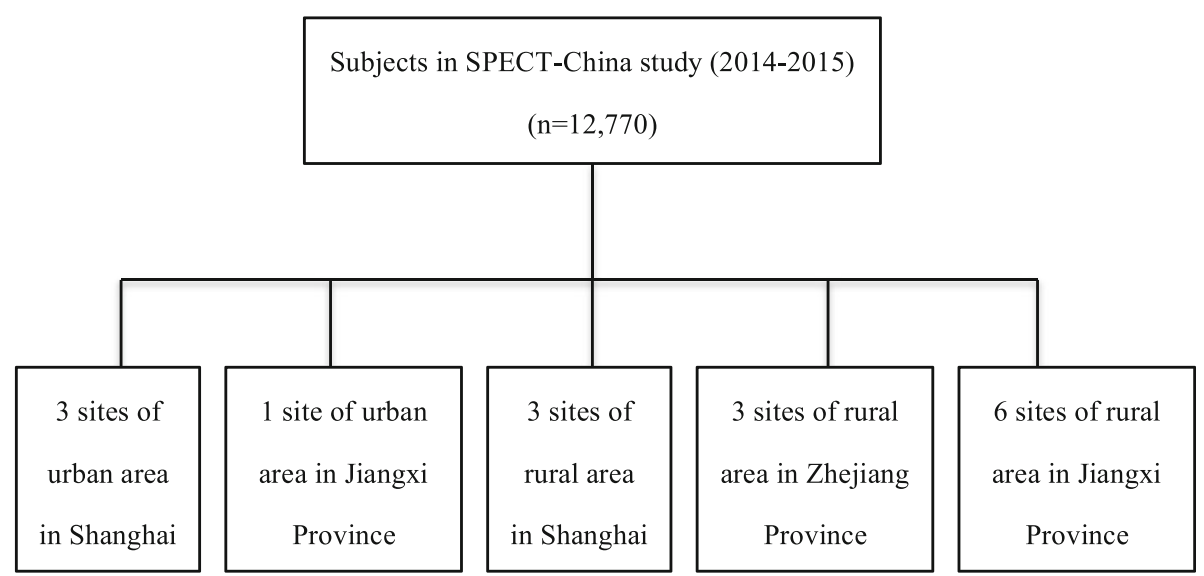

No uric acid data $(n=3,535)$

Subjects with UA data $(n=9,235)$

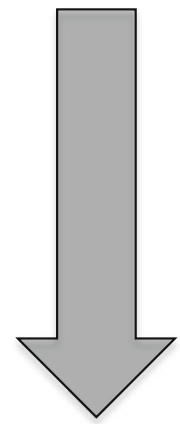

No vitamin $\mathrm{D}$ data $(\mathrm{n}=4)$

Gouty arthritis or CKD5 stage $(\mathrm{n}=10)$

Take anti-osteoporosis drugs $(\mathrm{n}=1)$

Subjects included in our study $(\mathrm{n}=9,220)$

Fig. 1 Flowchart of this study. We totally collected 12,770 subjects. After excluding participants who had missing data or specific disease states, finally, 9220 subjects were included

divided into quartiles. To compare the differences among quartiles, one-way ANOVA was used for continuous variables. Pearson's $\mathrm{X} 2$ test was used for categorical variables.

Pearson's correlation was used to analyze the relationship between uric acid and each potentially associated factor, including $25(\mathrm{OH}) \mathrm{D}$, blood glucose, blood pressure, lipids, BMI, WC and ALT. Linear regression analysis was conducted to investigate the independent associations of UA with $25(\mathrm{OH}) \mathrm{D}$. Logistic analysis was performed to investigate the increased risk of HUA for every $10-\mathrm{nmol} / \mathrm{L}$ increase in $25(\mathrm{OH}) \mathrm{D}$.

\section{Results}

Indexes comparison between different groups

In our study, we analyzed the association of $25(\mathrm{OH}) \mathrm{D}$ with UA in 9220 Chinese adults, including 3681 males (age $55.57 \pm 13.23$ years) and 5539 females (age $54.31 \pm$ 12.83 years). Levels of SUA levels were $352.07 \pm 79.25$ $\mathrm{nmol} / \mathrm{L}$ and $269.29 \pm 64.68 \mathrm{nmol} / \mathrm{L}$ in males and females, 
respectively. The proportion of HUA was $12.26 \%$. Blood glucose (FPG, HbA1c), lipids (TC, TG, LDL) and blood pressure (SBP, DBP) in HUA were higher than in the normal population. The HUA group also had a higher $\mathrm{BMI}$ and WC than did the normal group. There was also a significant difference in $25(\mathrm{OH}) \mathrm{D}$ in these two groups $(40.28 \pm 12.97$ vs. $42.22 \pm 13.23, P<0.001)$ (Table 1$)$.

\section{Comparison between different UA subgroups}

UA was categorized into quartiles, and different indexes were compared between quartiles. Subjects with higher UA displayed increased blood glucose (FPG, HbA1c), lipids (TC, TG, LDL) and blood pressure (SBP, DBP). Other parameters, such as $25(\mathrm{OH}) \mathrm{D}, \mathrm{ALT}, \mathrm{WC}$ and BMI, showed graded changes as UA increased $(P<0.001)$ (Table 2).

\section{Correlation of UA with other parameters}

SUA was positively associated with $25(\mathrm{OH}) \mathrm{D}(r=0.095$, $P<0.001)$. Moreover, it also had a positive correlation with blood glucose (FPG, HbA1c), lipids (TC, TG, LDL) and blood pressure (SBP, DBP). HOMAIR, ALT BMI and WC were also associated with UA in our cohort (Table 3).

Table 1 Baseline characteristics between different groups

\begin{tabular}{llll}
\hline Variables & Normal UA $(n=8090)$ & HUA $(n=1130)$ & $P$ value \\
\hline Age (years) & $54.56 \pm 12.94$ & $56.62 \pm 13.31$ & $<0.001$ \\
Male\% & 37.4 & 58.2 & $<0.001$ \\
FPG (mmol/L) & $5.57 \pm 1.50$ & $5.73 \pm 1.34$ & 0.001 \\
HbA1c (\%) & $5.68 \pm 0.99$ & $5.79 \pm 0.94$ & 0.001 \\
Fasting insulin (mIU/L) & $42.30 \pm 47.86$ & $54.67 \pm 62.35$ & $<0.001$ \\
HOMA-IR & $1.59 \pm 2.91$ & $2.15 \pm 4.04$ & $<0.001$ \\
ALT (IU/L) & $20.75 \pm 15.44$ & $28.06 \pm 20.61$ & $<0.001$ \\
TG (mmol/L) & $1.58 \pm 1.26$ & $2.37 \pm 2.39$ & $<0.001$ \\
TC (mmol/L) & $5.19 \pm 1.14$ & $5.44 \pm 1.10$ & $<0.001$ \\
LDL (mmol/L) & $3.25 \pm 0.81$ & $3.43 \pm 0.82$ & $<0.001$ \\
25(OH) D (nmol/L) & $40.28 \pm 12.97$ & $42.22 \pm 13.23$ & $<0.001$ \\
BMI (kg/m $\left.{ }^{2}\right)$ & $24.46 \pm 3.56$ & $26.33 \pm 3.45$ & $<0.001$ \\
WC $(\mathrm{cm})$ & $80.80 \pm 10.23$ & $87.12 \pm 9.25$ & $<0.001$ \\
SBP $(\mathrm{mmHg})$ & $131.76 \pm 21.74$ & $137.00 \pm 20.74$ & $<0.001$ \\
DBP $(\mathrm{mmHg})$ & $79.03 \pm 13.02$ & $82.94 \pm 13.13$ & $<0.001$ \\
Diabetes\% & $14.5 \%$ & $20.3 \%$ & $<0.001$ \\
Hypertension\% & $45.9 \%$ & $61.5 \%$ & $<0.001$ \\
\hline Da a & & &
\end{tabular}

Data are presented as the mean \pm standard deviation for continuous variables or as a number with proportion for categorical variables

FPG Fasting plasma glucose, ALT Alanine aminotransferase, TG Triglycerides, TC Total cholesterol, BMI Body mass index, WC Waist circumference, SBP Systolic blood pressure, $D B P$ Diastolic blood pressure

\section{Liner regression analysis of UA and $25(\mathrm{OH}) \mathrm{D}$}

After adjusting for gender, age, ALT, TG, SBP, HbA1c and BMI, SUA concentration was significantly associated with $25(\mathrm{OH}) \mathrm{D}$, with an unstandardized coefficient of 0.19 (95\%CI 0.08, 0.30). However, SBP did not have a significant association with SUA $(P=0.151)$ (Table 4$)$.

\section{Logistic regression analysis of UA}

It was found that $25(\mathrm{OH}) \mathrm{D}$, age, ALT, TG and BMI were positively associated with UA. Gender and HbA1c were negatively associated with UA. After adjustment were made for gender, age, ALT, TG, SBP, HbA1c and BMI, the incidence of HUA was increased $9.4 \%$ for every $10-\mathrm{nmol} / \mathrm{L}$ increase in $25(\mathrm{OH}) \mathrm{D}(P<0.001)$ (Table 5).

\section{Discussion}

We performed a cross-sectional study in the general population. The level of $25(\mathrm{OH}) \mathrm{D}$ was higher in hyperuricemic than in normouricemic subjects. Furthermore, $25(\mathrm{OH}) \mathrm{D}$ was positively associated with SUA, even after adjustments were made for different variants. The incidence of HUA increased $9.4 \%$ for every $10-\mathrm{nmol} / \mathrm{L}$ increase in $25(\mathrm{OH}) \mathrm{D}$.

The conclusions of some other studies were similar to ours. Sipahi $\mathrm{S}$ et al. found that a decrease in SUA was among the predictors of hypovitaminosis D [14]. However, several previous studies have concluded that HUA is associated with hypovitaminosis $\mathrm{D}[13,15,16]$. This finding seems to indicate a complicated relationship between vitamin D status and SUA.

Vitamin D produced in the skin or obtained from the diet should undergo two steps of metabolic activation to become the active hormone $\left(1,25(\mathrm{OH})_{2} \mathrm{D}\right)$. The first step, which results in 25-hydroxylated vitamin $\mathrm{D}$, is conducted mostly in the liver by hydroxylases. In the circulation, $25(\mathrm{OH}) \mathrm{D}$ is bound to vitamin D-binding protein (DBP). The next hydroxylation occurs after the complexes of $25(\mathrm{OH}) \mathrm{D}$ and DBP are reabsorbed from the glomerular filtrate at the proximal tubule of the kidney. The production of $1,25(\mathrm{OH})_{2} \mathrm{D}$ is regulated by specific hormones on the expression of CYP27B1 and CYP24A1. CYP27B1 activates vitamin D metabolites, while CYP24 A1(24-hydroxylase enzyme) inactivates both $25(\mathrm{OH}) \mathrm{D}$ and $1,25(\mathrm{OH})_{2} \mathrm{D}$, thus maintaining calcium and phosphate homeostasis [2]. The effect of vitamin D is far more extensive. The nonskeletal effects indicated that vitamin D was involved in a wide variety of pathologic processes. Some studies have reported that plasma $25(\mathrm{OH}) \mathrm{D}$ is associated with metabolic syndrome [17]. Additionally, vitamin D controls multiple biological processes, such as the following: cellular growth; angiogenesis or even modulation of the immune [18] and cardiovascular system [19], differentiation of keratinocytes [1]; and inhibition of the 
Table 2 Comparison between different UA subgroups

\begin{tabular}{|c|c|c|c|c|c|}
\hline & UA & & & & \\
\hline & Q1(45-242) & Q2(243-293) & Q3(294-352) & Q4(353-752) & $P$ for trend \\
\hline Age (years) & $51.92 \pm 12.68$ & $55.00 \pm 12.68$ & $56.60 \pm 12.65$ & $55.77 \pm 13.51$ & $<0.001$ \\
\hline FPG (mmol/L) & $5.47 \pm 1.58$ & $5.60 \pm 1.52$ & $5.63 \pm 1.49$ & $5.65 \pm 1.29$ & $<0.001$ \\
\hline $\mathrm{HbA1c}(\%)$ & $5.60 \pm 1.10$ & $5.71 \pm 1.01$ & $5.73 \pm 0.93$ & $5.73 \pm 0.89$ & $<0.001$ \\
\hline Fasting insulin (m|U/L) & $37.34 \pm 29.50$ & $41.39 \pm 38.96$ & $45.61 \pm 51.03$ & $50.79 \pm 69.64$ & $<0.001$ \\
\hline HOMA-IR & $1.37 \pm 1.87$ & $1.56 \pm 2.49$ & $1.73 \pm 2.97$ & $1.97 \pm 4.36$ & $<0.001$ \\
\hline ALT (IU/L) & $17.46 \pm 10.75$ & $20.20 \pm 17.18$ & $22.06 \pm 15.29$ & $26.91 \pm 19.41$ & $<0.001$ \\
\hline TG (mmol/L) & $1.30 \pm 0.95$ & $1.52 \pm 1.10$ & $1.73 \pm 1.47$ & $2.16 \pm 2.00$ & $<0.001$ \\
\hline TC (mmol/L) & $5.09 \pm 1.34$ & $5.22 \pm 1.05$ & $5.26 \pm 1.05$ & $5.31 \pm 1.08$ & $<0.001$ \\
\hline LDL (mmol/L) & $3.12 \pm 0.79$ & $3.29 \pm 0.81$ & $3.33 \pm 0.80$ & $3.36 \pm 0.82$ & $<0.001$ \\
\hline 25(OH) D (nmol/L) & $38.86 \pm 12.19$ & $40.07 \pm 13.22$ & $41.06 \pm 13.27$ & $42.11 \pm 13.14$ & $<0.001$ \\
\hline BMI (nmol/L) & $23.54 \pm 3.29$ & $24.35 \pm 3.70$ & $24.97 \pm 3.54$ & $25.92 \pm 3.44$ & $<0.001$ \\
\hline WC $(\mathrm{cm})$ & $76.70 \pm 9.42$ & $79.96 \pm 10.21$ & $83.14 \pm 9.60$ & $86.65 \pm 9.29$ & $<0.001$ \\
\hline SBP (mmHg) & $128.31 \pm 21.72$ & $132.01 \pm 22.50$ & $133.94 \pm 21.06$ & $135.40 \pm 20.76$ & $<0.001$ \\
\hline $\mathrm{DBP}(\mathrm{mmHg})$ & $76.71 \pm 12.75$ & $78.54 \pm 13.28$ & $80.60 \pm 12.70$ & $82.26 \pm 12.97$ & $<0.001$ \\
\hline
\end{tabular}

proliferation of breast [20], colon [21] and prostate cancer cells [22].

A high level of UA is considered to be associated with impaired renal function [23] and gouty arthritis [24]. Additionally, HUA may increase the risk of some diseases, such as CVD [25] or insulin resistance [26]. On the other hand, UA is a strong antioxidant. Nabipour I et al. found that a high level of UA was positively associated with higher bone mineral density (BMD) at all skeletal sites, serum calcium and $25(\mathrm{OH}) \mathrm{D}$, as well as a lower prevalence of fractures in older men [27]. It is hypothesized that when liver function is impaired, both the

Table 3 Pearson correlation of UA with other parameters

\begin{tabular}{lll}
\hline & UA & \\
\cline { 2 - 3 } & $r$ & $P$ \\
\hline Age (years) & 0.101 & $<0.001$ \\
FPG (mmol/L) & 0.041 & $<0.001$ \\
HbA1c (\%) & 0.043 & $<0.001$ \\
Fasting insulin (mIU/L) & 0.101 & $<0.001$ \\
HOMA-IR & 0.072 & $<0.001$ \\
ALT (IU/L) & 0.223 & $<0.001$ \\
TG (mmol/L) & 0.244 & $<0.001$ \\
TC (mmol/L) & 0.073 & $<0.001$ \\
LDL (mmol/L) & 0.100 & $<0.001$ \\
25(OH) D (nmol/L) & 0.095 & $<0.001$ \\
BMI (kg/m $\left.{ }^{2}\right)$ & 0.253 & $<0.001$ \\
WC $(\mathrm{cm})$ & 0.370 & $<0.001$ \\
SBP $(\mathrm{mmHg})$ & 0.126 & $<0.001$ \\
DBP $(\mathrm{mmHg})$ & 0.173 & 0.000 \\
\hline
\end{tabular}

production of UA and 25(OH) D decreases, because UA is produced in hepatocytes by xanthine oxidase, and vitamin $\mathrm{D}$ is hydroxylated in the liver to become 25(OH)D.

Estrogen may have influences on vitamin D and SUA $[28,29]$. There was a different relationship between vitamin D and SUA in premenopausal women and postmenopausal women [13]. Vitamin D insufficiency was significantly associated with elevated UA among postmenopausal Chinese Han women, but no significant association was found among premenopausal women. It has been hypothesized that estradiol (E2) may affect SUA through mechanisms involving renal clearance, secretion and reabsorption [30]. Our study population included men, premenopausal women and postmenopausal women. We adjusted for gender and age, but we did not adjust for menopausal status, so the effect of estradiol may be confounded.

Table 4 Association between UA (dependent variable) and potential predictors (independent variables) by linear regression

\begin{tabular}{llll}
\hline & $\mathrm{B}$ & $95 \% \mathrm{Cl}$ & $P$ \\
\hline 25OHD & 0.19 & $0.08,0.30$ & 0.001 \\
Gender & -73.67 & $-76.61,-70.72$ & $<0.001$ \\
Age & 0.47 & $0.35,0.59$ & $<0.001$ \\
ALT & 0.46 & $0.37,0.55$ & $<0.001$ \\
TG & 8.51 & $7.53,9.49$ & $<0.001$ \\
SBP & 0.05 & $-0.02,0.13$ & 0.151 \\
HbA1C & -6.24 & $-7.75,-4.74$ & $<0.001$ \\
BMI & 3.62 & $3.20,4.04$ & $<0.001$
\end{tabular}

Data are expressed as unStandardized B $(95 \% \mathrm{Cl})$. The enter procedure was used 
Table 5 Association between UA (dependent variable) and potential predictors (independent variables) by logistic regression

\begin{tabular}{llll}
\hline & $\operatorname{Exp}(\mathrm{B})$ & $95 \% \mathrm{Cl}$ & $P$ \\
\hline 25(OH) D (binned) & 1.094 & $1.04,1.15$ & $<0.001$ \\
Gender & 0.53 & $0.46,0.61$ & $<0.001$ \\
Age & 1.01 & $1.01,1.02$ & $<0.001$ \\
ALT & 1.01 & $1.01,1.02$ & $<0.001$ \\
TG & 1.22 & $1.17,1.28$ & $<0.001$ \\
SBP & 1.00 & $1.00,1.01$ & 0.044 \\
HbA1C & 0.914 & $0.85,0.98$ & 0.013 \\
BMI & 1.10 & $1.08,1.12$ & $<0.001$ \\
\hline
\end{tabular}

Data are expressed as $\operatorname{Exp}(\mathrm{B})(95 \% \mathrm{Cl})$

In addition, other factors may affect the SUA and $25(\mathrm{OH})$ D levels, such as sun exposure, vitamin D supplementation, and the use of certain drugs. Elevated parathyroid hormone (PTH) levels are thought to reduce renal urate excretion, although the exact mechanism remains unclear [31]. It was found that teriparatide therapy increased incidence of HUA in postmenopausal women [32]. SUA level returned to the pretreatment level after stopping treatment of PTH [33]. On the other hand, PTH can induce the expression of CYP27B1 and inhibit CYP24A1, as a result, the production of 1 , $25(\mathrm{OH})_{2} \mathrm{D}$ increases [2]. Therefore, hyperparathyroidism or PTH replacement can influence both SUA and vitamin D. We excluded the subjects who took antiosteoporosis drugs, thus, no participant used PTH replacement.

UA is initially filtered in the kidney. Acute renal failure is associated with increased circulating SUA concentration as a decrease of renal excretion [10]. Reduced nephron mass and/or $1 \alpha$-hydroxylase enzyme activity has been shown to be associated with a decline in $1,25(\mathrm{OH})_{2} \mathrm{D}$ levels in patients with CKD [11]. As the substrate of 1 , $25(\mathrm{OH})_{2} \mathrm{D}$, levels of $25(\mathrm{OH}) \mathrm{D}$ might be increased. Chen $\mathrm{W}$ et al. found that hyperuricemia suppresses $1 \alpha-$ hydroxylase, leading to lower $1,25(\mathrm{OH})_{2} \mathrm{D}$ and higher $\mathrm{PTH}$ in rats [30]. However, vitamin D is converted to $25(\mathrm{OH}) \mathrm{D}$ in the liver by 25 -hydroxylase. Some studies have shown that treatment of HUA increases $1,25(\mathrm{OH})_{2} \mathrm{D}$ levels with no change in $25(\mathrm{OH}) \mathrm{D}[16,34,35]$. In our study, we only measured the serum level of $25(\mathrm{OH}) \mathrm{D}$ to reflect vitamin $\mathrm{D}$ status. Thus, impaired renal function might raise SUA and 25(OH) D levels simultaneously.

Osteoporosis is a common public health problem in China. The prevalence of osteoporosis in China has increased over the past years, affecting more than onethird of people aged 50 years and older [36]. The most common prevention and treatment of osteoporosis is vitamin D supplementation. Although the causality between SUA and vitamin D was not clear, we should pay attention to the risk of hyperuricemia induced by excessive vitamin D supplements. More clinical trials are necessary to investigate the effect of vitamin D supplementation on serum UA.

Our study has several limitations that must be considered. First, we did not consider seasonal variation in $25(\mathrm{OH}) \mathrm{D}$ concentrations. Second, data on sun exposure were not available. Third, we did not measure serum calcium and parathyroid hormone, and we could not determine whether the association of $25(\mathrm{OH})$ D with SUA was partly mediated by calcium or secondary hyperparathyroidism, although individuals using anti-osteoporosis drugs were excluded. Fourth, the exact type and dose of alcohol were not available. In our questionnaire, we only recorded drinking status as never drinking and past or current drinking. In addition, diet-related data were not available in our study, so the influence of diet on SUA levels was not considered.

\section{Conclusion}

Our findings in the eastern China population revealed that serum UA was positively associated with $25(\mathrm{OH}) \mathrm{D}$, and the incidence of HUA increased $9.4 \%$ for every 10 $\mathrm{nmol} / \mathrm{L}$ increase in $25(\mathrm{OH}) \mathrm{D}$. Higher levels of serum $25(\mathrm{OH}) \mathrm{D}$ may be a potential predictor of HUA.

\section{Abbreviations \\ UA: Uric acid; CVD: Cardiovascular disease; SUA: Serum uric acid; FPG: Fasting plasma glucose; WC: Waist circumference; HUA: Hyperuricemia; VDRs: Vitamin D receptors; NAFLD: Nonalcoholic fatty liver disease; CDK: Chronic kidney disease; HOMA-IR: Homeostasis model assessment of insulin resistance; BMI: Body mass index; SBP: Systolic blood pressure; DBP: Diastolic blood pressure; TC: Total cholesterol; TG: Triglycerides; LDL: Low-density lipoprotein; ALT: Alanine aminotransferase; BMD: Bone mineral density; PTH: Parathyroid hormone}

\section{Acknowledgements}

The authors thank all team members and participants in the SPECT-China study.

\section{Authors' contributions}

YLL and BH designed the study. JC and FZX collected the data. YCC, NJW and YC conducted the statistical analysis. YCC, JC, YC and CC conducted the investigation. YCC wrote, reviewed and edited the manuscript. All authors read and approved the final manuscript.

\section{Funding}

This study was supported by National Natural Science Foundation of China (91857117, 81670717); Science and Technology Commission of Shanghai Municipality (19140902400, 18410722300); the Major Science and Technology Innovation Program of Shanghai Municipal Education Commission (2019-0107-00-01-E00059); Commission of Health and Family Planning of Pudong District (PWZxq2017-17); Municipal Human Resources Development Program for Outstanding Young Talents in Medical and Health Sciences in Shanghai (2017YQ053); Shanghai JiaoTong University School of Medicine (19XJ11007). The funders played no role in the design or conduct of the study, collection, management, analysis, or interpretation of data or in the preparation, review, or approval of the article.

\section{Availability of data and materials}

The datasets used and/or analyzed during the current study are available from the corresponding authors on reasonable request. 


\section{Ethics approval and consent to participate}

The authors state that this study was conducted in accordance with the Declaration of Helsinki. All the recruited participants have provided written informed consent before the investigation. The study protocol was approved by the Ethics Committee of Shanghai Ninth People's Hospital, Shanghai Jiao Tong University School of Medicine (approval number 2013(86)).

\section{Consent for publication}

Not applicable.

\section{Competing interests}

The authors declare that they have no competing interests.

Received: 27 January 2020 Accepted: 27 May 2020

Published online: 03 June 2020

\section{References}

1. Bikle DD. Vitamin D metabolism and function in the skin. Mol Cell Endocrinol. 2011;347(1-2):80-9.

2. Skowron K, Pawlicka I, Gil K. The role of vitamin D in the pathogenesis of ocular diseases. Folia Med Cracov. 2018;58(2):103-18.

3. Maesaka JK, Fishbane S. Regulation of renal urate excretion: a critical review. Am J Kidney Dis. 1998:32(6):917-33.

4. Ames BN, Cathcart R, Schwiers E, Hochstein P. Uric acid provides an antioxidant defense in humans against oxidant-and radical-caused aging and cancer: a hypothesis. Proc Natl Acad Sci U S A. 1981;78(11):6858-62.

5. Bobulescu IA, Moe OW, et al. Renal transport of uric acid: evolving concepts and uncertainties. Adv Chronic Kidney Dis. 2012;19(6):358-71.

6. $X u C, Y u C, X u L$, et al. High serum uric acid increases the risk for nonalcoholic fatty liver disease: a prospective observational study. PLoS One. 2010;5(7):e11578.

7. Ryu S, Chang Y, Kim SG, et al. Serum uric acid levels predict incident nonalcoholic fatty liver disease in healthy Korean men. Metabolism. 2011; 60(6):860-6.

8. Gustafsson D, Unwin R. The pathophysiology of hyperuricaemia and its possible relationship to cardiovascular disease, morbidity and mortality. BMC Nephrol. 2013;14:164

9. Katsiki N, Karagiannis A, Athyros VG, et al. Hyperuricaemia: more than just a cause of gout? J Cardiovasc Med. 2013;14(6):397-402

10. Ejaz AA, Mu W, Kang DH, Roncal C, Sautin YY, et al. Could uric acid have a role in acute renal failure? Clin J Am Soc Nephrol. 2007;2(1):16-21.

11. Levin A, Bakris GL, Molitch $M$, et al. Prevalence of abnormal serum vitamin D, PTH, calcium, and phosphorus in patients with chronic kidney disease: results of the study to evaluate early kidney disease. Kidney Int. 2007;71(1):31-8.

12. Li YC. Vitamin D: roles in renal and cardiovascular protection. Curr Opin Nephrol Hypertens. 2012:21(1):72-9.

13. Peng $H$, Li H, Li C, et al. Association between vitamin D insufficiency and elevated serum uric acid among middle-aged and elderly Chinese Han women. PLoS One. 2013;8(4):e61159.

14. Sipahi S, Acikgoz SB, et al. The Association of Vitamin D status and Vitamin $D$ replacement therapy with glycemic control, serum uric acid levels, and microalbuminuria in patients with type 2 diabetes and chronic kidney disease. Med Princ Pract. 2017:26(2):146-51.

15. Yilmaz $H$, Kaya $M$, Sahin $M$, et al. Is vitamin $D$ status a predictor of glycaemic regulation and cardiac complication in type 2 diabetes mellitus patients? Diabetol Metab Syndr. 2012;6(1):28-31.

16. Takahashi S, Yamamoto T, Moriwaki Y, et al. Decreased serum concentrations of 1,25(OH)2-vitamin D3 in patients with gout. Metabolism. 1998:47(3):336-8.

17. Lu L, Yu Z, Pan A, Hu FB, Franco OH, et al. Plasma 25-hydroxyvitamin D concentration and metabolic syndrome among middle-aged and elderly Chinese individuals. Diabetes Care. 2009:32(7):1278-83.

18. van Etten E, Mathieu C. Immunoregulation by 1,25-dihydroxyvitamin D3: basic concepts. J Steroid Biochem Mol Biol. 2005:97(1-2):93-101.

19. Li YC. Vitamin D regulation of the renin-angiotensin system. J Cell Biochem. 2003:88(2):327-31.

20. Swami S, Raghavachari N, Muller UR, Bao YP, Feldman D. Vitamin D growth inhibition of breast cancer cells: gene expression patterns assessed by cDNA microarray. Breast Cancer Res Treat. 2003;80(1):49-62.
21. Pálmer HG, González-Sancho JM, Espada J, et al. Vitamin D (3) promotes the differentiation of colon carcinoma cells by the induction of E-cadherin and the inhibition of beta-catenin signaling. J Cell Biol. 2001;154(2):369-87.

22. Zhao XY, Peehl DM, Navone NM, Feldman D. 1a,25-Dihydroxyvitamin D3 inhibits prostate cancer cell growth by androgen-dependent and androgen-independent mechanisms. Endocrinology. 2000;141(7):2548-56.

23. Okada $Y, \operatorname{Sim} X$, et al. Meta-analysis identifies multiple loci associated with kidney function-related traits in East Asian populations. Nat Genet. 2012; 44(8):904-9.

24. Reginato AM, Mount DB, et al. The genetics of hyperuricaemia and gout. Nat Rev Rheumatol. 2012;8(10):610-21.

25. Grassi D, Desideri G, Ferri C. New insight into urate-related mechanism of cardiovascular damage. Curr Pharm Des. 2014;20(39):6089-95.

26. Zhu $Y, H u Y$, et al. High uric acid directly inhibits insulin signalling and induces insulin resistance. Biochem Biophys Res Commun. 2014:447(4):707-14.

27. Nabipour I, Sambrook PN, et al. Serum uric acid is associated with bone health in older men: a cross-sectional population-based study. J Bone Miner Res. 2011;26(5):955-64.

28. Zittermann A. Vitamin D in preventive medicine: are we ignoring the evidence? Br J Nutr. 2003:89(5):552-72.

29. Liu B, Wang $T$, Zhao $H$, Yue $W, Y u H$, et al. The prevalence of hyperuricemia in China: a meta-analysis. BMC Public Health. 2011;11:832.

30. Yahyaoui R, Esteva I, et al. Effect of long-term administration of cross-sex hormone therapy on serum and urinary uric acid in transsexual persons. J Clin Endocrinol Metab. 2008;93(6):2230-3.

31. Hisatome I, Ishimura $M$, et al. Renal handling of urate in two patients with hyperuricemia and primary hyperparathyroidism. Intern Med. 1992; 31(6):807-11.

32. Miller PD, Schwartz EN, Chen P, Misurski DA, Krege JH. Teriparatide in postmenopausal women with osteoporosis and mild or moderate renal impairment. Osteoporos Int. 2007;18(1):59-68.

33. Neer RM, Arnaud CD, Zanchetta JR, Prince R, Gaich GA, et al. Effect of parathyroid hormone (1-34) on fractures and bone mineral density in postmenopausal women with osteoporosis. N Engl J Med. 2001;344: 1434-41.

34. Chen W, Roncal-Jimenez C, Lanaspa M, et al. Uric acid suppresses 1 alpha hydroxylase in vitro and in vivo. Metabolism. 2014:63(1):150-60.

35. Vanholder R, Patel S, Hsu CH. Effect of uric acid on plasma levels of 1,25(OH)2D in renal failure. J Am Soc Nephrol. 1993;4(4):1035-8.

36. Chen P, Li Z, Hu Y. Prevalence of osteoporosis in China: a meta-analysis and systematic review. BMC Public Health. 2016;16(1):1039.

\section{Publisher's Note}

Springer Nature remains neutral with regard to jurisdictional claims in published maps and institutional affiliations.

Ready to submit your research? Choose BMC and benefit from:

- fast, convenient online submission

- thorough peer review by experienced researchers in your field

- rapid publication on acceptance

- support for research data, including large and complex data types

- gold Open Access which fosters wider collaboration and increased citations

- maximum visibility for your research: over $100 \mathrm{M}$ website views per year

At BMC, research is always in progress.

Learn more biomedcentral.com/submissions 